\title{
Popular Alcoholic Beverages in Russia with Special Reference to Quality and Toxicity
}

Keywords: Alcohol drinking; Alcohol toxicity; Alcohol policies; Wine: Russia

\begin{abstract}
Alcohol consumption in Russia is usually associated with vodka. During the anti-alcohol campaign (1985-1989), many factories producing vodka from grain or potatoes were dismantled. During the 1990s, technical alcohol (synthetic or cellulosic), finding no demand from the stagnating industry, was used for production of vodka, wine imitations, beer and other beverages. Synthetic alcohol imported from other countries was used for the same purposes. Apart from vodka, wines fortified by addition of distilled alcohol were abundantly consumed in the former Soviet Union. Especially in the period between the two anti-alcohol campaigns (1972-1985), the part taken by fortified wines was considerable. Some cheapest fortified wines were poor quality, causing deeper intoxications than vodka. However, many inexpensive wines made from grapes or fruit by fermentation with addition of distilled alcohol were acceptable quality. Technically correct production turned out to be expensive after the transition to the market economy. Many popular wines disappeared around 1990: some of their names have further been used for low quality products. However, an improvement tendency of sold beverages has been noticed approximately since the last decade.
\end{abstract}

\section{Introduction}

The aim of this review was to draw attention to certain aspects of alcohol consumption in Russia: consequences of the anti-alcohol campaign (AAC) (1985-1989), toxicity of some legally sold alcoholic beverages, offences against alcohol-dependent people. Governmental alcohol policies, consumption dynamics and significance of alcohol for the public health have been overviewed previously $[1,2]$. Furthermore, this review tries to analyze the question, why the massive consumption of fortified wines (FW) in the former Soviet Union (SU) is not readily perceptible from the literature and mass media. Apparently, there are two reasons. First, some cheapest FW were more toxic than vodka. It is obviously easier to add poor-quality alcohol to red or brownish fluids with different tastes and flavors, than to the rather standard product such as vodka. Second, FW were, in general, natural products: they were made from grapes or fruit by fermentation with addition of distilled alcohol. Many FW were acceptable quality. Obviously, their production in a technically correct manner turned out to be expensive after the transition to the market economy. The prime cost of FW, manufactured from grapes or fruit, was higher than that of vodka, but many of them were sold at lower prices per unit of pure alcohol (Table 1).

\section{Dynamics of wine consumption}

FW with alcohol concentration 16-19 \% by volume were massively produced and sold in the former SU (Table 2) till the
Journal of

\section{Addiction \& Prevention}

\section{Sergei V. Jargin*}

Department of Pathology, People's Friendship University of Russia, Russian Federation, University of Russia, Russia

\section{*Address for Correspondence}

Sergei V. Jargin, Department of Pathology, People's Friendship University of Russia, Russian Federation, University of Russia, Clementovski per 6-82, 115184 Moscow, Russia, Tel: +7 495 9516788; E-mail: sjargin@mail.ru

Submission: 21 October, 2017

Accepted: 15 November, 2017

Published: 24 November, 2017

Copyright: ( 2017 Jargin SV. This is an open access article distributed under the Creative Commons Attribution License, which permits unrestricted use, distribution, and reproduction in any medium, provided the original work is properly cited.

beginning of the AAC, when vodka price doubled, but inexpensive wines were still available for some time, even though their quality worsened and there were long queues at retail outlets. The increase

Table 1: Prices in rubles of alcoholic beverages in the former SU during the 1970s (own data).

\begin{tabular}{|c|c|c|c|c|c|}
\hline Category & $\begin{array}{c}\text { Typical } \\
\text { examples }\end{array}$ & $\begin{array}{l}\text { Bottle } \\
\text { price }\end{array}$ & $\begin{array}{l}\text { Volume } \\
\text { (liters) }\end{array}$ & $\begin{array}{c}\text { Alcohol } \\
\text { concentration by } \\
\text { volume }(\%)\end{array}$ & $\begin{array}{c}\text { Price } \\
\text { per } 100 \\
\text { ml of } \\
\text { pure } \\
\text { alcohol }\end{array}$ \\
\hline Cheapest FW & $\begin{array}{l}\text { Portwein } 72, \\
\text { Bile Mitsne, } \\
\text { cheapest } \\
\text { vermouth }\end{array}$ & $<1.80$ & 0.8 & $\sim 18$ & $<1.25$ \\
\hline $\begin{array}{l}\text { Inexpensive } \\
\text { FW, } \\
\text { acceptable } \\
\text { quality }\end{array}$ & Portwein Kavkaz & 2.13 & 0.75 & 18 & 1.58 \\
\hline $\begin{array}{l}\text { Acceptable to } \\
\text { good quality }\end{array}$ & Portwein Iveria & 2.3 & 0.75 & 18 & 1.7 \\
\hline $\begin{array}{l}\text { Quality FW } \\
\text { (marochnoe) }\end{array}$ & $\begin{array}{l}\text { Crimean } \\
\text { Portwein }\end{array}$ & 3.2 & 0.75 & $\sim 18$ & 2.37 \\
\hline $\begin{array}{l}\text { Cheapest } \\
\text { vodka }\end{array}$ & Vodka & 3.5 & 0.5 & 40 & 1.75 \\
\hline $\begin{array}{l}\text { Cheapest } \\
\text { cognac }\end{array}$ & Three stars & 8 & 0.5 & 40 & 4 \\
\hline Cheap beer & Zhigulevskoe & 0.25 & 0.5 & $\sim 3.5$ & $\sim 1.43$ \\
\hline
\end{tabular}

Notes: Ruble was not convertible during the 1970s. The bottle deposit price 0.12 rubles is to be added to the prices from the Table 1 . The prices are given for Moscow; outside the Capital, somewhat cheaper FW could be found. During the 1980 s prior to the AAC, the price of a 0.5 liter vodka bottle increased gradually from 3.5 to 6 rubles. Before 1970, a 0.5 liter bottle of the cheapest cognac cost 4 rubles.

Table 2: Wine production in the former SU per annum ( $m$ dal) $[3,4,7,8]$.

\begin{tabular}{|c|c|c|c|c|}
\hline Types of wine/years & $\mathbf{1 9 6 6}$ & $\mathbf{1 9 7 0}$ & $\mathbf{1 9 7 5}$ & $\mathbf{1 9 8 4}$ \\
\hline Grape & 119 & 250 & 277 & 367 \\
\hline Fruit-and-berry & 25.8 & 38.7 & 114 & 108 \\
\hline Champagne-type & 4.5 & 6.9 & 10.4 & 19.9 \\
\hline
\end{tabular}

Notes: Fruit-and-berry wines were mostly fortified. Many inexpensive wines of Port, Vermouth and undeterminable types were statistically counted as grape wines [4,5]. 
in wine production prior to the AAC occurred in accordance with the policy aimed at partial replacement of vodka by wine and beer; especially, quality (marochnoe) wine was promoted. The quality was supervised by authorities [3,4]. However, substandard wines were also sold at that time and there was a deterioration tendency. Some cheapest wines e.g. notorious Solntsedar, produced supposedly from Algerian materials [5], as well as some Algerian (according to labels) red dry wines, were noticed to provoke vomiting. In the late 1970s these wines disappeared from the Soviet market. In the period 19801985 prior to the onset of AAC, the quality decline was acknowledged by the literature; flavoring additives and sugar were used increasingly to disguise faults [6,7]. However, production continued growing (Table 2).

The quality of sparkling wines was noticed to be worsening; "Soviet Champagne" often smelled yeast. High-yield low quality sorts of grapes were increasingly used for wine production. Hygienic requirements were often disregarded; there was no regular microbiological control. Some yeast cultures used for the fermentation were not sufficiently pure. Temperature regimes of fermentation were not always adhered to. Acidity of many wines was high [8], which was noticed also by consumers. In the author's opinion, quality decrease in the early 1980 s was tolerated by authorities planning to replace inexpensive natural wines by sweetish stained-and-flavored imitations. The new products have often been given popular names e.g. Portwein 72, which used to be acceptable quality. The notorious Portwein 777 (Figure 1) appeared in the 1980s being bad-quality from the beginning. Portwein 777 is often mentioned by the media as "bormotukha" (poor quality FW) apparently with the goal to generally discredit popular FW destined to disappear from the market. The number 777 is meaningless; but earlier numbered varieties (Portwein 13, 33, 72) had been developed by winemakers and were recognizable. As for the fruit-and-berry wines, after the onset of the AAC their production was planned to be abandoned [9], which indeed happened according to our observations. Today, natural fruit-and-berry FW is produced in Belorussia.

The term "fortified wine" (FW), common in the past, is officially out of use in Russia today. According to the law modified 2012,

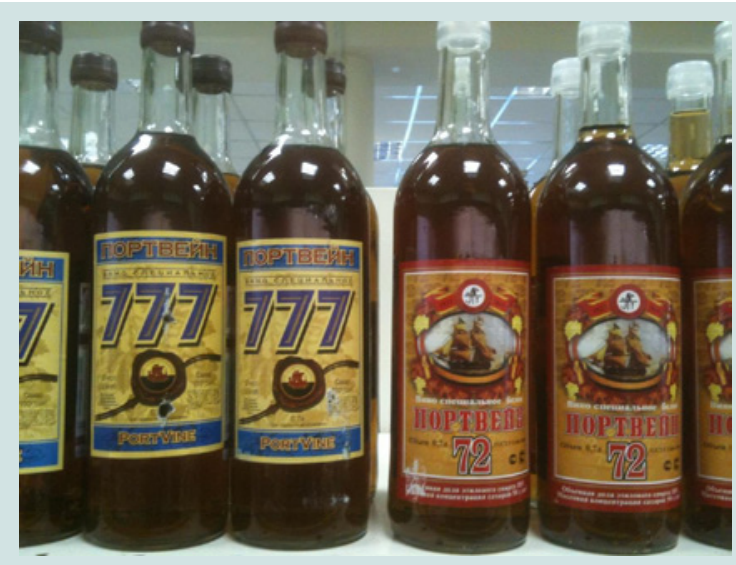

Figure 1: Portwein 72 was cheap fortified wine of acceptable quality during the Soviet time. It has disappeared; and the popular name is used for selling of flavored sweetish alcohol solutions. Portwein 777 appeared later in the 1980 s and has been poor quality from the beginning. wines with added alcohol made from grapes (or from fruit in case of fruit wine) were named liqueur wines, while those fortified with grain or potato alcohol, which has been usual practice in Russia, were classified as "vinnyi napitok - wine beverage". In regard to the latter term the law has been changed again in 2015: wines fortified with grain alcohol were renamed as "special liqueur wines" [10]. In the author's opinion, this is a misnomer because liqueur presupposes sweetness, while not all FW are sweet. The term "FW" seems to be optimal [11]. Properly purified distilled alcohol of grain origin was reported to have lower concentrations of non-ethanol substances than that of grape origin $[12,13]$, which might be of importance if higher doses are regularly consumed. Probably for that reason, domestic FW were often preferred by Russian drinkers. Companies with female participation often preferred sweet (fortified up to 14$16 \%)$ or sparkling wines, which were inexpensive and often good quality. Especially in the period between the two AACs (1972-1985), the part taken by FW was considerable, being comparable with that of vodka. Wines were not regularly available in remote areas of North and Siberia, but consumers welcomed wine shipments.

\section{Imitations of foreign wines and spirits}

Imitation of foreign wines in the former SU has long traditions. Numerous old labels, for example, of Madeira (spelled Madera)] from the year 1954 or Pinot Gris from 1962, produced in Crimea, are shown in the book [14]. During the Soviet time, imitations of many internationally known wines and spirits were manufactured: Port, Jerez (Sherry), Tocai (Tokay), Champaign, Kagor (Cahors), Cognac and some liqueurs such as Chartreuse and Benedictine. Gin and whiskey were produced as well. Port, Madera and Vermouth were especially popular. Many imitations were natural products manufactured more or less on the basis of original methods. Some sorts of Champagne, Port, Madeira, Sherry and Cognac were good quality; several generations enjoyed them, when importation from the West was scarce or inexistent. Thanks to this practice, many Russians are acquainted with internationally known wines and spirits recognizing today the originals. Quality wine and Cognac were affordable to the broad public during the Soviet time: Cognac was approximately twice as expensive as vodka; before 1970 the difference was even smaller (Table 1).

With the beginning of the AAC in May 1985, quality of alcoholic beverages deteriorated. After the AAC, together with inflation and transition to the market economy, the prices and quality levels of alcoholic beverages diversified; surrogates in bottles with vodka or wine labels were legally sold in shops and kiosks. New labels appeared and disappeared; beverage names and qualities correlated poorly. Imported products had sometimes been good in the beginning, later being replaced by counterfeit imitations. Well-known wines and cognacs disappeared, changed their taste or were replaced by surrogates made from technical alcohol with flavor and color additives $[5,12,15]$. The somewhat astringent taste and odor of technical alcohol is known as it was regularly stolen from some factories, institutes of physics, technology etc. Inexpensive wines containing added alcohol but also some natural wine have come to the fore recently. There is information that some additives interfered with potency. There have been also more expensive Port and Madera, which used to smell technical alcohol; today, however, the quality seems to be improving. 
Apparently, younger consumers are getting accustomed to the products containing alcohol from non-edible sources. Some older people deplore such development. A consumer often does not know, whether he or she is drinking a counterfeit imitation or a foreign product adapted to the Russian market. The relative proportion of counterfeit beverages on sale is difficult to determine; it seems to be higher in smaller towns than in Moscow. The quality of counterfeit beverages depends on their origin: they can be manufactured by regular factories, being concealed from excise duties, or "in garages" [16]. Since the 1990s, the Caucasus has been known as a nationwide source of cheap alcoholic beverages, a considerable part being poor quality $[17,18]$. Almost all vodka concealed from excise duties in North Ossetia was reported to be produced from technical alcohol [15]. Unpredictability and averagely poor quality of alcohol probably contributed to a decrease in consumption. Development of Port, Sherry, Madera, Cognac (Figure 2), whiskey and Calvados has been continued [19-25]. In some publications, imitations of Cognac are named brandy [26], and those of Port - "wine of Portwein type" [20]. However, both continue to be sold with the labels Cognac or Portwein. Cognac exported to other countries would be named brandy, while in Russia it is sold with the label Cognac [26]; the same pertains to Sekt vs. Champagne (Figure 3). The brand "Russian Cognac" is being

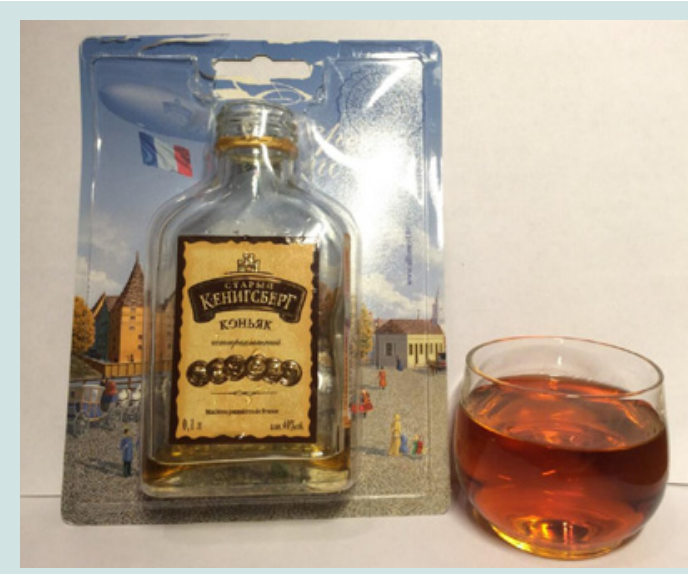

Figure 2: Cognac of the new sort "Old Königsberg".

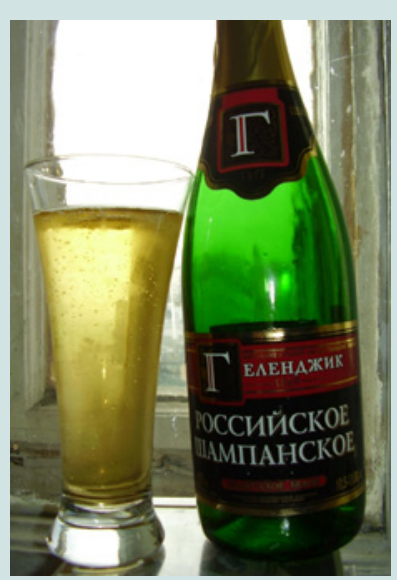

Figure 3: "Russian Champagne" has almost completely replaced "Sovie Champagne" produced since the 1930s. promoted [27].

As far as we know, in the West are sold only original products of the above-named types, in accordance with the Protected Geographical Status framework. The problem waits for its solution: under which names and labels the imitations can be legitimately produced and sold. The optimal way, in our opinion, would be preservation of some former denominations such as Crimean Madera since consumers are accustomed to them. Champagne-type wines could be named Sekt, Brut, or sparkling wine, Port-type wines - Ruby or Tawny, or be numbered (e.g. Portwein 33 or 72) as they were in the former SU; these names can be used under the condition of adherence to the original formula.

\section{Discussion and Conclusion}

The fact that the Soviet state, at various times, encouraged alcohol sales is known to the international community [28]. Alcohol drinking at workplaces was tolerated among workers and intelligentsia at many factories, institutions, laboratories etc. In places these traditions persisted in the post-Soviet time, although drinking at workplaces has declined. Some festivals were associated with drinking, the best example being New Year: celebration started well before midnight; then, at midnight, sparkling wine named Champagne was consumed; then followed a continuation, often till the daybreak. Other festivals associated with alcohol were the Women's Day on the $8^{\text {th }}$ of March and professional holidays such as the Builder's Day on the second Sunday of August, when many people related to this profession consumed alcoholic beverages. Birthdays etc. have been celebrated by many working teams. In workers', students' and intelligentsia groups, ringleaders could be observed, who manipulated others towards binge drinking. Non-drinkers were often stigmatized as outsiders.

As a part of the anti-alcohol measures in 1972, the sales of vodka on Sundays and between 7 p.m.-11 a.m. all other days were prohibited. However, wines were sold after 7 p.m. till the closure of shops at 8-10 p.m. and Sundays. The cheapest FW was named bormotukha - the "mumbler": intoxicated individuals sometimes mumbled indeed, having lost control of their speech and behavior. It was apparently caused by poor quality alcohol i.e. compounds other than ethanol. Admixtures were masked by the taste of wine or, increasingly since the 1980s, by artificial flavors. Many workers finished their shifts around 5 p.m.; considering queues at retail outlets, they could have started drinking vodka but continued with FW or consumed the latter only. FW were used for heavy binge drinking; they were often better tolerated than vodka, which at higher doses sometimes provoked vomiting e.g. when the second $250 \mathrm{ml}$ glass was drunk in a hurry, without meal and accompanying drink such as beer or Pepsi. For older people wine or beer is often preferable to vodka, as the latter can damage atrophic mucosa. Drinkers generally knew that it was not advisable to drink FW after vodka: it often resulted in vomiting and deeper intoxications.

The AAC launched 1985 was initially effective, but ended with a failure and was accompanied by increased consumption of homemade moonshine (samogon), technical alcohol-containing liquids and lotions [1,5,29]. Many well-known wines disappeared around 1990; some of their names continued to be used for legally sold surrogates $[1,30]$. After 1988, alcohol consumption increased, while 
vodka enhanced its share in the total [31,32]. Apparently, the ACC and its predictable failure were exploited for political and economical purposes. The AAC destabilized the Soviet society; the widespread drunkenness in the 1990s acted as anesthesia during a surgery: workers and intelligentsia did not protest against privatizations of state properties by former administration and party functionaries, which occurred not always in accordance with the law. Moreover, it can be speculated that if the society would not be destabilized by the AAC, Chernobyl accident and disintegration of the SU did not happen.

During the AAC, many distilleries producing vodka from grain and potatoes were closed and dismantled. At the same time, technical alcohol met no demand from stagnating industry. Official permissions to use alcohol from non-edible raw materials for production of beverages were issued during the 1990s [5,12]. The permissions have later been revoked but, on the background of disregard for some laws and regulations, the use of technical alcohol has been continued. It was demonstrated in animal experiments that synthetic and cellulosic alcohol are more toxic than that from edible sources [33]. Later on, purified synthetic and cellulosic ethanol was claimed to be compatible with requirements to beverage alcohol [12]; however, one can never be sure that purification was sufficient. Note that animal experiments may overestimate toxicity for humans of alcohol produced from edible sources compared to cellulosic or synthetic ethanol. Thousands years of adaptation of some human populations to alcohol included adaptation to by-products of natural fermentation. Synthetic alcohol has another spectrum of admixtures: presence or higher concentrations of sec- and tert-butanol, butanone, crotonaldehyde, acetone, diethyl ether, acetaldehyde etc. [12] Adaptation of humans to some new by-products may be lacking. This topic needs further research. Declarations by authoritative writers that "the problem is not quality but quantity" [5] tended to distract public attention from toxicity of legally sold alcoholic beverages.

After the abolition in 1992 of the state monopoly on alcohol, the country was flooded by domestic and imported alcohol of low quality. Sales of falsified beverages through legally operating shops, kiosks and eateries occurred generally with the knowledge and sometimes under participation of authorities or their members. It is well known in Russia that legally sold alcoholic beverages sometimes caused up to severe and lethal intoxications. The following absolute numbers of lethal poisonings with alcohol-containing fluids were reported: 199821,800, 1999-24,100, 2000-27,200; another increase was in 2006 [34]. About a half of lethal poisonings with alcohol-containing fluids in some areas during the 1990s were reported to be caused by legally sold beverages, while in many lethal cases the blood alcohol concentration was relatively low [35]. The unrecorded figures were certainly higher, as many undiagnosed diseases, unnatural causes of death including poisonings, have been misclassified post mortem as resulting from cardiovascular diseases [2,36]. Overestimation of the cardiovascular morbidity/mortality on one hand and of its cause-effect relationship with alcohol e.g. in [35-39] on the other hand, tends to ascribe deaths from undiagnosed and untreated diseases, poisonings etc., to alcohol abuse, thus shifting responsibility from authorities onto the patients.

For example, the number of poisonings with marked jaundice during the period August-November 2006 was reported to be 12,611, including 1189 lethal cases, allegedly caused by disinfectant Extrasept-1 containing apart from ethanol $0.08-0.15 \%$ of diethyl phthalate and $0.1-0.14 \%$ of polyhexamethylene guanidine hydrochloride (PHMG). The liquid was sold in vodka bottles [40,41]. Cholestatic hepatitis with "a marked inflammatory component" was described in liver biopsies [40]. Apart from PHMG, "chloride compounds" [42,43], i.e. organochlorides have been discussed as possible causative factors. In particular, carbon tetrachloride used in dry cleaning was presumed as a cause of poisonings with acute hepatotoxicity. The latter seems to be more probable as PHMG and diethyl phthalate have no strong hepatotoxicity [29]; in rat experiments with PHMG no inflammation in the liver was detected [44].

Some publications create impression that consumers deliberately purchase non-beverage alcohol for drinking [42,45], which shifts responsibility for poisonings from authorities to consumers. According to our observations and generally known facts, drinking of alcohol-containing technical liquids (lotions, window cleaner etc.) decreased abruptly after the failure of the AAC in 1989, when vodka, beer and other beverages have become easily available and relatively cheap. The only major exceptions are tinctures from the pharmacy: some people purchase them not because of the price but as they hope for better quality alcohol than vodka from the shop. In December 2016, 77 deaths were reported from a mass poisoning in Irkutsk; more details and references are in [29]. According to available information, the poisoning was caused by the bath lotion Boyaryshnik (Hawthorn) reportedly containing 93\% ethanol, while chemical analysis found that it contained methanol. In the author's opinion, the poisoning could have been caused by hawthorn (Crataegus) tincture from the pharmacy containing $70 \%$ ethanol. The hawthorn tincture is the form of medicinal alcohol most frequently used by drinkers in Russia [46,47]. No information on Hawthorn bath lotion containing 93\% of ethanol has been found. There could have been misinformation intended to disguise the fact that methanol was used as substitute for medicinal alcohol. As for disinfectants like the above-mentioned Extrasept-1, to the best of our knowledge, nobody would deliberately buy them for drinking. It should be stressed that apart from limited sales of samogon mainly to neighbors in rural areas, there is no illegal or "black" alcohol retail market in Russia: all beverages are sold through legally operated shops, eateries and previously also kiosks. This fact is not always understood by foreign experts, which can be illustrated by the following citation: "... when faced with a branded vodka at the minimum price and a counterfeit vodka, the consumer will always choose the branded vodka" [48]. In fact, consumers are usually unable to distinguish between branded and counterfeit vodka as it is sold at the same shops and looks identical or almost identical.

In conclusion, alcohol consumption and heavy binge drinking tend to decline in Russia [49,50]; but alcohol still remains a part of life; and it can be eliminated only together with life. The last AAC has demonstrated it demonstrated it. The concept of absolute sobriety propagated by the well-known surgeon Fedor Uglov (19042008) [51] seems to be insincere, unconstructive and unrealistic. Uglov applied lung resections and bronchoscopies without sufficient indications, overviewed in [52]. Figuratively speaking, the AAC was a surgery performed without sufficient indications. After the AAC, the average life expectancy in Russia decreased dramatically; for the period 1993-2001 in men it was estimated to be 58-59 years 
$[5,31,36]$. The causes of the enhanced mortality have been discussed previously: limited availability of the modern health care, chronic diseases often left untreated, toxicity of some legally sold alcoholic beverages, crime against alcohol-depended people with appropriation of their apartments and houses, resulting in homelessness and premature death, violations of medical ethics $[1,2,52]$. The latter topic needs a brief comment. Compulsory treatments with questionable clinical indications were applied to alcoholics: prolonged intravenous infusions, pyrotherapy with sulfozine (oil solution of sulphur for intramuscular injections) and pyrogenal, sorbent hemoperfusion, plasmapheresis, endolymphatic and endobronchial drug delivery, endoscopic and surgical biopsies of internal organs without clear indications also for research, endoscopic cholangiopancreatography and angiography [53,54]; more details and references are in $[52,55,56]$. The aim of these methods was sometimes research; ideation of punishment, irresponsibility, insufficient use of foreign literature and training of medical specialists have apparently played a role $[5,57]$. Note that excessive endovascular and endoscopic manipulations can lead to a transmission of viral hepatitis [58], which happened to treated alcoholic patients. A combination of viral and alcoholic liver injury is known to be unfavorable. Compulsory treatment of alcoholics with tuberculosis included repeated bronchoscopies, while procedural quality assurance has not always been optimal. The author observed patients in distress after repeated bronchoscopies performed with questionable clinical indications; more details are in [52]. Furthermore, it was noticed that vigorous apomorphine- and/or mechanically induced vomiting as emetic therapy of alcohol dependence induced bleeding in some tuberculosis patients [59]. In 1994 it was reported that $60 \%$ of patients from a "phthisio-narcological hospital" for compulsory treatment of alcoholics with tuberculosis tried runaway while a half of them was brought back by the police (militsia) [60]. Today, however, the law enforcement must be more efficient.

\section{Future Research}

In regard to future research, poor quality alcohol i.e. potentially toxic substances other than ethanol are of importance. Gas chromatography combined with flame ionization detection (GCFID), using a column that would separate contaminants, and gas chromatography - mass spectrometry (GC-MS) are applicable for assessment of alcoholic beverages and detection of toxic admixtures $[12,61]$. Toxicity of alcohol from edible and non-edible raw materials and admixtures to alcoholic beverages should be studied in bioassays by independent researchers. In the author's opinion, addition of alcohol from non-edible sources (cellulosic or synthetic) to beverages should be prohibited or, at least, its presence must be clearly indicated on the labels.

\section{References}

1. Jargin SV (2016) Alcohol and alcoholism in Russia: insider's observations and review of literature. J Addict Prev 4: 6 .

2. Jargin SV (2017) Cardiovascular mortality in Russia: a comment. Cardiovasc Diagn Ther 2017: 1-2.

3. Editorial (1971) Main development directions of the winemaking industry Winemaking and Viticulture of the USSR: 2-5.

4. Editorial (1976) Enhance production efficiency of fruit-and-berry wines. Winemaking and Viticulture of the USSR: 3-6.
5. Nemtsov AV (2009) Alcoholic history of Russia: contemporary period Moscow, Russia.

6. Editorial (1984) High quality for fruit-and-berry wines. Winemaking and Viticulture of the USSR: 2-4

7. Shaituro LF (1984) Plan is the law of economical life. Winemaking and Viticulture of the USSR: $2-5$

8. Editorial (1971) The five-year plan completed successfully. Winemaking and Viticulture of the USSR: 2-4

9. Kas'ko SV (1985) Complete the plan, enhance the quality. Winemaking and Viticulture of the USSR: $2-5$

10. Sarkisian S (2015) Russian wines. Deutsches Druckwerk, Moscow, Russia.

11. Vine RP, Harkness EM, Linton SJ (2002) Winemaking: from grape growing to marketplace ( $2^{\text {nd }}$ edn $)$. Springer US, New York, USA, pp. 477.

12. Nuzhnyi VP, Rozanets VV, Savchuk SA (2011) Chemistry and toxicology of ethyl alcohol and beverages made on its basis: chromatographic analysis of alcoholic beverages ( $2^{\text {nd }}$ edn $)$. Knizhnyy dom "LIBROKOM", Moscow, Russia.

13. Preobrazhenskii AA, Moiseenko DA, Kozub GI (1967) Technology of strong wines of Portwein type. Cartea Moldoveneasca, Chisinau, Europe.

14. Kruchina EN, Shtyrlin MA, Sogoyan KR (2004) Crimean wines. Izdatelstvo Zhigulskogo, Moscow, Russia.

15. Shaidullina ED (2014) Criminal responsibility for illegal manufacturing and trade with alcoholic products. Juridical Institute, Kazan, Russia.

16. Urumbaeva RN (2009) On influence of different factors on the scale of illegal market of alcohol in Russian Federation. Manufacture of Alcohol and Liqueur \& Vodka Products: 4-5.

17. Guguchkina TI, lakuba luF, Lunina LB (2005) Development of evaluation methods of authenticity of grape wines. In: Innovations and efficiency of manufacturing processes in viticulture and winemaking. Russ Acad Agric Sci: 309-314.

18. Guguchkina TI, Ageeva NM, Rudenko AG, Senkina EV (2005) Quality control of viticulture products of Kuban. In: Innovations and efficiency of manufacturing processes in viticulture and winemaking. Russ Acad Agric Sci: 320-324.

19. Adzhiev AM, Gadzhiev GR, Grigoriants BV (2005) Some scientific and practical aspects of the Cognac production development in Dagestan. In: Innovations and efficiency of manufacturing processes in viticulture and winemaking. Russ Acad Agric Sci 2: 188-190.

20. Agafonova NM (2014) Technology development of Portwein-type wines with low sugar contents. Dissertation, National Research Institute, Magarach, Yalta, Russia.

21. Alekseeva RV (2009) Development of manufacturing technology of the special wine Portwein from perspective sorts of grapes. Dissertation, Kuban Technology University, Krasnodar, Russia.

22. Blagoz AR, Ageeva NM (2007) Manufacturing of Calvados in the Republic of Adygea. Winemaking and Viticulture (Moscow): 16-17.

23. Kushkhova RB (2014) Technology development of strong vintage (marochnoe) wines of Madera-type. Dissertation, National Research Institute, Magarach, Yalta, Russia.

24. Lubchenkov PP, Lubchenkova NA, Lubchenkov AA, Pakhunov BG, Pakhunov VB, et al. (2005) Special features of manufacturing of "Praskoveiskoe" whiskey. In: Innovations and efficiency of manufacturing processes in viticulture and winemaking. Russ Acad Agric Sci: 180-188.

25. Tsherviak SN (2014) Technology development of Sherry (Jerez) wines and wine materials for production of dry table Sherry. Dissertation, National Research Institute, Magarach, Yalta, Russia.

26. Khiabakhov TS (2005) Main improvement directions of manufacturing technology of Russian brandy. In: Innovations and efficiency of manufacturing processes in viticulture and winemaking. Russ Acad Agric Sci: 191-196.

27. Information (2015) The largest manufacturers established Cognac Union. 
Winemaking and Viticulture: 58.

28. McKee M (1999) Alcohol in Russia. Alcohol Alcohol 34: 824-829.

29. Jargin SV (2016) Questionable information on poisonings by alcohol surrogates. Interdiscip Toxicol 9: 83-84.

30. Govorin NV, Sakharov AV (2012) Alcohol-related mortality. Ivan Fedorov, Tomsk, Russia.

31. Ryan M (1995) Alcoholism and rising mortality in the Russian Federation BMJ 310: 646-648.

32. WHO (2011) Russian Federation key indicators. Global Information System on Alcohol and Health (GISAH), World Health Organization, Geneva, Swizerland.

33. Nuzhnyi VP (1995) Toxicological characteristic of ethyl alcohol, alcoholic beverages and of admixtures to them. Voprosy Narkologii: 65-74.

34. Pelipas VE, Miroshnichenko LD (2011) Problems of the alcohol policy. In: Ivanets NN, Vinnikova MA (eds), Alcoholism. Moscow, Russia, pp. 817-851.

35. Nuzhnyi VP, Kharchenko VI, Akopian AS (1998) Alcohol abuse in Russia is an essential risk factor of cardiovascular diseases development and high population mortality (review). Ter Arkh 70: 57-64.

36. Davydov MI, Zaridze DG, Lazarev AF, Maksimovich DM, Igitov VI, et al (2007) Analysis of mortality in Russian population. Vestn Ross Akad Med Nauk: $17-27$

37. Nemtsov AV (2002) Alcohol-related human losses in Russia in the 1980s and 1990s. Addiction 97: 1413-1425.

38. Paukov VS, Erokhin luA (2004) Pathologic anatomy of hard drinking and alcoholism. Arkh Patol 66: 3-9.

39. Vertkin AL, Zairat'iants OV, Vovk El (2009) Final diagnosis. Geotar-Media Moscow, Russia.

40. Ostapenko YN, Brusin KM, Zobnin YV, Shchupak AY, Vishnevetskiy MK, et al (2011) Acute cholestatic liver injury caused by polyhexamethyleneguanidine hydrochloride admixed to ethyl alcohol. Clin Toxicol (Phila) 49: 471-477.

41. Luzhnikov EA (2014) Medical Toxicology. Geotar-Media, Moscow, Russia.

42. Khaltourina D, Korotayev A (2016) Alcohol control policies and alcoholrelated mortality in Russia: reply to Razvodovsky and Nemtsov. Alcohol Alcohol 51: 628-629.

43. Nuzhnyi VP, Rozhanets VV, Savchuk SA (2010) Chemistry and toxicology of ethyl alcohol and beverages on its basis. Moscow, Russia.

44. Bonitenko Elu, Sentsov VG, Grebeniuk AN (2013) Clinic, diagnostics, treatment and forensic-medical examination of intoxication by alcohol and its surrogates. Elbi, Saint Petersburg, Russia.
45. Razvodovsky YE (2015) The effect of beverage type on alcoholic psychoses rate in Russia. Alcohol Alcohol 50: 200-205.

46. Gil A, Polikina O, Koroleva N, McKee M, Tomkins S, et al. (2009) Availability and characteristics of nonbeverage alcohols sold in 17 Russian cities in 2007. Alcohol Clin Exp Res 33: 79-85.

47. Monakhova YB, Kuballa T, Leitz J, Lachenmeier DW (2011) Determination of diethyl phthalate and polyhexamethylene guanidine in surrogate alcohol from Russia. Int J Anal Chem 2011: 704795.

48. Bailey A (2014) Campaign, simulation, or what? President Medvedev's antialcohol initiative, 2009-2012. In: Materials of the Fifth International Scientificand-Practical Conference "Alcohol in Russia", October 24-25, 2014, Ivanovo, Russia, pp. 119 -124.

49. Perlman FJ (2010) Drinking in transition: trends in alcohol consumption in Russia 1994-2004. BMC Public Health 10: 691.

50. Radaev V (2015) Impact of a new alcohol policy on homemade alcohol consumption and sales in Russia. Alcohol Alcohol 50: 365-372.

51. Uglov FG (1995) Suicides. Newspaper "Vozrozhdenie", Suppl. Saint Petersburg, Russia.

52. Jargin SV (2017) Invasive procedures with questionable indications used in Russia: Recent history. J Surgery 5: 8.

53. Makhov VM, Abdullin RG, Gitel' EL, Zavodnov Vla, Podzolkov VI, et al. (1996) Visceral lesions in alcoholism. Ter Arkh 68: 53-56.

54. Krut'ko VS (1990) Pneumonia in patients with pulmonary tuberculosis and alcoholism. Probl Tuberk: 64-66.

55. Jargin SV (2015) Alcohol abuse and alcoholism in Russia. Int J Emerg Ment Health 17: 603-604.

56. Jargin SV (2015) Some aspects of renal biopsy for research. Int J Nephrol Kidney Fail 1: 1-5.

57. Jargin SV (2013) Some aspects of medical education in Russia. Am J Med Studies 1: 4-7.

58. Saludes V, Esteve M, Casas I, Ausina V, Martró E (2013) Hepatitis C virus transmission during colonoscopy evidenced by phylogenetic analysis. J Clin Virol 57: 263-266

59. Entin GM (1990) Treatment of alcoholism. Meditsina, Moscow, Russia

60. Rudoi NM, Dzhokhadze VA, Chubakov TCh, Stadnikova AV (1994) Current status and perspectives in hospital treatment of patients with tuberculosis complicated with alcohol abuse. Probl Tuberk: 8-10.

61. Wiśniewska P, Śliwińska M, Dymerski T, Wardencki W, Namieśnik J (2015) Application of gas chromatography to analysis of spirit-based alcoholic beverages. Crit Rev Anal Chem 45: 201-225. 